\title{
Exploration and Practice of Mixed Teaching Reform in Advanced Mathematics Course Against OBE Mode
}

\author{
Yanling Li \\ Dalian Neusoft University of Information \\ Dalian, China
}

\author{
Hao Chen \\ Dalian Neusoft University of Information \\ Dalian, China
}

\begin{abstract}
By studying the current situation of mixed teaching reform in China and foreign countries, and from the perspective of students, OBE is used to carry out mixed teaching reform in advanced mathematics courses. The online teaching and classroom teaching are organically combined, and an integrated assessment method is designed to objectively and effectively reflect the student's learning status and learning effect. This paper hopes to improve students' interest in mathematics from multiple perspectives and dimensions, develop students' ability to apply mathematical knowledge to solve practical problems, and enable students to have mathematical thinking.
\end{abstract}

Keywords-mixed teaching reform; advanced mathematics; teaching mode; online platform

\section{INTRODUCTION}

Advanced Mathematics is an important public basic course for students after entering university. Advanced mathematics courses are the basis for students 'follow-up professional courses, and also the key to cultivating students' logical thinking ability, abstract thinking ability, and analytical problem solving ability. However, it is precisely because of the abstractness, logic and rigor of advanced mathematics that many students are afraid of mathematics and have no confidence or interest in learning advanced mathematics.

In the previous teaching mode, the classroom was the main carrier of student learning, and the teacher was the dominant player in the classroom. What is presented is more teachers teaching knowledge in the classroom, students passively accepting knowledge. Students complete homework in accordance with the teacher's requirements after class, but students do not have appropriate self-study channels and effective learning materials. There are certain restrictions on both preview and review, coupled with the limitation of teachers, students have less time for tutoring and answering questions after class, and the learning effect is naturally not ideal. In order to change this situation, in order to reflect the subject status of students, improve students' learning effect and enthusiasm, the research and practice of the mixed teaching model based on OBE has become the main research topic and reform direction of many universities.

\section{The CurRent Status of Research ON MiXed TEACHING MODELS}

With the development of information technology and the acceleration of knowledge upgrading, the channels for students to acquire new knowledge are gradually increasing. The traditional teaching mode of combining blackboard and PPT can no longer meet the interest and motivation of students to acquire knowledge, resulting in a series of problems such as low learning efficiency and poor learning results. In order to change this situation, many colleges and universities carry out educational and teaching reforms combined with high-tech means such as the Internet and information technology.

In 2008, Brian Alexander and Dave Comill proposed the concept of MOOC, an open online learning model. The introduction of this model has attracted wide attention from many colleges and universities, and has also greatly impacted the traditional teaching model. Many universities have thought deeply about this and tried to reform. After experimenting for a period of time, I gradually found that the MOOC model does have many advantages over the traditional teaching model, such as resource sharing, convenient learning, and independent of time and occasion. Of course, there are many shortcomings in the MOOC model. For example, it is difficult to detect learning effects, there is no uniformity between online and offline, teachers cannot monitor the learning status of students, and it is difficult to understand the students' mastery of knowledge. Therefore, it is difficult to adjust the teaching progress in the classroom according to the learning situation of the students, it is not possible to improve the learning efficiency in the classroom, and finally it is difficult to realize the teaching concept of OBE. Therefore, in order to integrate the online and offline teaching organically, and take the students learning effect as the guide, after analyzing the respective advantages of the online course and the offline traditional teaching mode, a mixed teaching mode is proposed.

\section{DESIGN AND PRACTICE OF MiXed TEACHING REFORM IN ADVANCED MATHEMATICS}

In the context of the popularization of education, students have poor mathematical analysis, calculation and deduction 
mathematics courses. It is the basis for implementing the reform of mixed teaching, the construction of course content and the assessment of courses. The construction of teaching resources mainly includes video construction, case library construction, and test question library construction.

In order to better cooperate with offline teaching and enrich students' learning resources after class, we recorded videos of important chapters after sorting out advanced mathematical knowledge points. For example, the concept of function limit, the concept of function continuity, the concept of derivative, the concept of differentiation, the concept of integral, and so on. Through video learning, students can have a macro-level understanding of knowledge, can better enter the offline classroom learning, and can clearly understand the key points and difficulties of this section. They can learn with problems, which improves the efficiency and motivation of learning. At the same time, we classify knowledge points and record difficult and difficult videos as materials for students to learn in class. Where students have doubts in the classroom and understand poor knowledge points, they can watch videos after class to continue learning, which is equivalent to the "tutor" of student learning. Video resources are the top priority in the construction of mixed teaching reform resources. We use "refined" videos, and each video is about 15 minutes in length. In the design and recording of videos, we always adhere to taking students as the main body, learning effects as the purpose, problemoriented, and the principle of application, and carefully design each video, and modify it repeatedly in the later period, and strive to bring good learning to students effect.

In order to reflect the applied type of mathematics, and to cultivate students' ability to apply mathematics and to solve practical problems, and to cultivate students' interest in learning, a case base is built according to the knowledge points of advanced mathematics courses, for example, "the best allocation of labor and capital", "cell reproduction", "the time of the murder", etc. It is to urge students to apply their knowledge to solve mathematical problems in actual production and life. In this process, students' mathematical modeling ability, ability of self-learning by consulting data, mathematical thinking, and mathematical innovation ability are cultivated.

In order to effectively urge students to study offline and to test their learning effects, a question bank is compiled. The question bank is mainly divided into two parts, one is the "pre-test question bank" and the other is the "post-test question bank". The pre-test question bank is mainly to examine the students' understanding of the basic concepts of mathematics, and to test the effect of online video learning. Through self-study, students can directly find the answers to the exercises on the provided learning materials. The posttest question bank mainly tests the learning effect after studying online and offline classrooms. The breadth and depth of the test questions are also improved to a certain extent compared to the test questions in the pre-test question bank. The test link mainly relies on the existing online and mobile platforms.
2) Construction of teaching resources: The construction of teaching resources plays a vital role in the implementation of mixed teaching reform in advanced 
to solve simple differential equations. In the classroom teachers can focus more on training students 'ability to build differential equations, that is, to cultivate students' ability to abstract mathematical models from actual problems, that is, mathematical modeling capabilities. However, the development of this ability is very important for students to learn other professional courses in the future.

After class: Equip students with relevant learning materials such as videos for important and difficult points, and provide students with learning packages for after-school learning difficulties in the classroom. Students can effectively complete their homework by studying in class and consolidating and reviewing after class. Students also participate in post-tests. Post-test questions also rely on the mobile platform and call the post-test question bank. Teachers can monitor students' learning in time according to their answers. For failing students, you can take unexpected measures, warnings, etc., and reflect them in ordinary grades, so that students have a sense of crisis in ordinary learning. In this way, you can avoid the phenomenon of "temporarily holding your feet" before the exam. In addition, the teacher can arrange a paper assignment once at the end of each chapter, check the students 'completion, and grasp the students' standardization of mathematical symbol writing and the rationality of mathematical language application.

The reform of the mixed teaching of advanced mathematics curriculum requires the integrated design before, during, and after class to form a reasonable and effective closed loop, so as to truly be student-centered and improve student learning results.

4) Auxiliary support for mixed teaching reform: In order to improve the learning effect of students, realize the organic integration of online and offline teaching, increase the number of tests and strengthen the management of online learning, the burden is undoubtedly increase on teachers, such as grade correction, problem feedback, learning monitoring and other tasks. However, the current teaching conditions are limited, so it can increase the number of student teaching assistants. Among senior students, students with strong sense of responsibility and high math scores are selected to write assistants in mathematics to assist teachers to complete certain online and offline teaching management tasks. For example, use the time of late self-study to provide counseling and answer questions for students during the preview and review, assist the teacher to sort out feedback of post-test questions, correct homework, online forum management, platform maintenance, etc.

\section{Teaching Methods and Means}

Under the mixed teaching reform model, the teaching methods of advanced mathematics courses are mainly problem-based teaching methods, and multiple teaching methods are used in combination to stimulate students learning interest, cultivate their learning ability, and improve their learning effects. The case-based problem-based teaching method is adopted to encourage students' research- 


\section{REFERENCES}

based learning. Part of the knowledge points are based on the teaching method and practice method based on intensive lecture and practice to improve the learning effect. In short, different teaching methods can be selected according to different content, and the application is flexible.

The teaching method mainly adopts a combination of blackboard writing + PPT + online platform + mobile platform + Mathematica auxiliary teaching. The blackboard mainly shows the process of proof, deduction, deduction or calculation. PPT mainly displays complex icons, animations, definition theorem text, exercise questions, etc. Online platform: Students rely on online platforms for online learning. Mobile platform: Students participate in pre-tests, post-tests, and participate in classroom interactions. Mathematica assisted teaching: use mathematics software to assist teaching, weaken complex calculations, pay more attention to practical results, and conform to the characteristics of IT colleges; Using live broadcast to assist teaching, cater to students 'tastes, conform to the law of cognition, and adapt to students' ability to accept.

\section{The Teaching EFfect Evaluation Model of the REFORM OF MIXED TEACHING IN ADVANCED MATHEMATICS}

The evaluation of the learning effect of the advanced mathematics curriculum of the mixed teaching reform can adopt an evaluation method combining formative evaluation and final evaluation. Formative evaluation mainly refers to the evaluation of students 'learning attitudes and learning processes, which can include student attendance, student classroom performance, students' pre-test results, post-test results, paper assignments, online learning, etc. Designing formative evaluation can organically combine students' online learning effects with offline learning, so as to increase students' participation in online learning, gradually develop the habit of self-study, and improve students' ability to learn for life. Final evaluation refers to the final roll test, which assesses the students' grasp of basic mathematical knowledge and the ability of students to use mathematical knowledge to solve practical problems.

\section{CONCLUSION}

The reform of mixed teaching in advanced mathematics courses is still in the exploration stage, and has achieved certain results in practical applications. The application of mixed teaching reform can well integrate the advantages of traditional teaching and online teaching. Students can use the information platform to obtain a large number of learning resources that are suitable for them, and they can learn more autonomously without the constraints of time and place. Teachers can also monitor the learning of students, adjust the content of lessons, and develop more teaching models. The reform of mixed teaching requires us to continuously think, improve, and improve, apply it better in teaching, and improve the learning effect of students.
[1] Zhao Lei, Zhu Hong, Ma Hongliang. New Opportunities for Mixed Teaching in Colleges and Universities: MOOC Perspective [J]. Educational Development Research, 2015 (17): 50-55. (in Chinese)

[2] Wang Zezheng, Yao Jia. Practice and reflection on SPOC mixed teaching mode in advanced mathematics [J]. University Mathematics, 2017 (1): 91-95. (in Chinese)

[3] He Chaoyang, Ou Yufang, Cao Qi. Enlightenment of flipping classroom teaching model in American universities [J]. Research in Higher Engineering Education, 2014 (2): 148-151. (in Chinese) 